\title{
ORIGINAL
}

\section{The contribution of frailty, cognition, activity of daily life and comorbidities on outcome in acutely admitted patients over 80 years in European ICUs: the VIP2 study}

Bertrand Guidet ${ }^{1 *}$ (D) Dylan W. de Lange ${ }^{2}$, Ariane Boumendil ${ }^{3}$, Susannah Leaver ${ }^{4}$, Ximena Watson ${ }^{5}$, Carol Boulanger ${ }^{6}$, Wojciech Szczeklik ${ }^{7}$, Antonio Artigas ${ }^{8}$, Alessandro Morandi ${ }^{9}$, Finn Andersen ${ }^{10}$, Tilemachos Zafeiridis ${ }^{11}$, Christian Jung ${ }^{12}$, Rui Moreno ${ }^{13}$, Sten Walther ${ }^{14}$, Sandra Oeyen ${ }^{15}$, Joerg C. Schefold ${ }^{16}$, Maurizio Cecconi ${ }^{17,18}$, Brian Marsh ${ }^{19}$, Michael Joannidis ${ }^{20}$, Yuriy Nalapko ${ }^{21}$, Muhammed Elhadi22, Jesper Fjølner ${ }^{23}$, Hans Flaatten ${ }^{24,25}$ for the VIP2 study group

(c) 2019 Springer-Verlag GmbH Germany, part of Springer Nature

\begin{abstract}
Purpose: Premorbid conditions affect prognosis of acutely-ill aged patients. Several lines of evidence suggest geriatric syndromes need to be assessed but little is known on their relative effect on the 30-day survival after ICU admission. The primary aim of this study was to describe the prevalence of frailty, cognition decline and activity of daily life in addition to the presence of comorbidity and polypharmacy and to assess their influence on 30-day survival.
\end{abstract}

Methods: Prospective cohort study with $242 \mathrm{ICUs}$ from 22 countries. Patients 80 years or above acutely admitted over a six months period to an ICU between May 2018 and May 2019 were included. In addition to common patients' characteristics and disease severity, we collected information on specific geriatric syndromes as potential predictive factors for 30-day survival, frailty (Clinical Frailty scale) with a CFS $>4$ defining frail patients, cognitive impairment (informant questionnaire on cognitive decline in the elderly (IQCODE) with IQCODE $\geq 3.5$ defining cognitive decline, and disability (measured the activity of daily life with the Katz index) with $A D L \leq 4$ defining disability. A Principal Component Analysis to identify co-linearity between geriatric syndromes was performed and from this a multivariable model was built with all geriatric information or only one: CFS, IQCODE or ADL. Akaike's information criterion across imputations was used to evaluate the goodness of fit of our models.

Results: We included 3920 patients with a median age of 84 years (IQR: 81-87), 53.3\% males). 80\% received at least one organ support. The median ICU length of stay was 3.88 days (IQR: 1.83-8). The ICU and 30-day survival were 72.5\% and $61.2 \%$ respectively. The geriatric conditions were median (IQR): CFS: 4 (3-6); IQCODE: 3.19 (3-3.69); ADL: 6 (4-6); Comorbidity and Polypharmacy score (CPS): 10 (7-14). CFS, ADL and IQCODE were closely correlated. The multivariable analysis identified predictors of 1-month mortality (HR; 95\% Cl): Age (per 1 year increase): $1.02(1 .-1.03, p=0.01$ ), ICU admission diagnosis, sequential organ failure assessment score (SOFA) (per point): $1.15(1.14-1.17, p<0.0001)$ and

\footnotetext{
*Correspondence: bertrand.guidet@aphp.fr

${ }^{1}$ Sorbonne Université, INSERM, Institut Pierre Louis d'Epidémiologie et

de Santé Publique, Saint Antoine Hospital, AP-HP, Hôpital Saint-Antoine, service de réanimation, F75012 Paris, France

Full author information is available at the end of the article
}

\section{勿 Springer}


CFS (per point): $1.1(1.05-1.15, p<0.001)$. CFS remained an independent factor after inclusion of life-sustaining treatment limitation in the model.

Conclusion: We confirm that frailty assessment using the CFS is able to predict short-term mortality in elderly patients admitted to ICU. Other geriatric syndromes do not add improvement to the prediction model. Since CFS is easy to measure, it should be routinely collected for all elderly ICU patients in particular in connection to advance care plans, and should be used in decision making.

Keywords: Critical care, Outcome, Prediction, Elderly, Frailty, Cognitive functioning, Activities of daily living, Comorbidity

\section{Introduction}

The number of very old patients admitted to the intensive care unit (ICU) is rising, which parallels the increase in the proportion of elderly people in most developed countries [1]. In the past decade this has been identified as a potential health challenge because these patients aged 80 and above consume a disproportionally large part of the health care budget, while the mortality rates are consistently reported to be higher than in younger patients [2]. However, it is important to separate unplanned from planned ICU admissions, since the latter group has a much better outcome [3]. In unplanned admissions the overall 30-day mortality of ICU patients is approximately $40 \%$ [4]. Long-term mortality (6 months or 12 months) is most often $50 \%$ or above [5]. This high mortality translates into suffering in patients and relatives and moral distress in care-givers. It is, therefore, of utmost importance to better identify elderly patients with an expected good outcome including a post discharge acceptable quality of life.

Previous research has shown that age and severity of illness at admission only partly explain the chance of survival of elderly patients and traditional prognostic scoring systems are often inaccurate [6]. In the very old patients the ability to cope with severe stressors like critical illness seems to be more related with the geriatric syndromes, like frailty [4], cognitive decline $[7,8]$ and a reduced performance on the activity of daily life (ADL) scale in addition to comorbidity. However, the impact and relationship of this premorbid functioning on the outcome of acutely admitted elderly ICU patients have not been established [7, 8].

In this study, using the European Very elderly Intensive Patient (VIP) network, our primary aim was to document the prevalence of three common geriatric syndromes: frailty, cognitive impairment and disability in addition to the presence of comorbidity and polypharmacy, and to assess their influence on 30 days' survival.

\section{Take-home message}

In this prospective multinational study of 3920 very old intensive care patients ( $\geq 80$ years), clinical frailty scale alone described geriatric syndromes. Cognition and activity of daily life did not add to the prediction model for 1-month survival after ICU admission.

\section{Methods \\ Design and setting}

This was a prospective observational study in 242 ICUs from 20 European countries, plus Turkey and Libya. The participating ICU characteristics were: mean number of beds: 15; mean number of ICU admission in year 2017: 955; percentage of patients 80 years of age or older admitted in 2017: 17\%. Each participating ICU is listed in electronic supplement material (ESM1) and recruitment per country is presented in ESM2. The inclusion period was from May 2018 to May 2019. Most of the patients were included during the 2018-2019 winter season (ESM3). The 30-day follow-up ended on July 152019.

The study was coordinated through the health services resource and outcome (HSRO) section of the European society of intensive care medicine (ESICM). Each country had a national coordinator (NC) responsible for ICU recruitment and application for national or regional ethical and regulatory study approval. Institutional research ethic board approval was obtained from each study site. Five countries were allowed to recruit patients without prior written informed consent while others had to collect informed consent from patient or their legal representative [9]. Individual ICUs were asked to include consecutive patients for a 6-month period in the 1-year study period and were allowed to stop after 20 included patients. All patients were followed until 30 days after ICU admission. A dedicated web site (www.VIP2study. com) was set up to facilitate information about the study and study progress and to allow for data entry using an electronic case record form CRF (supplemental 1). The study is registered on ClinicalTrials.gov (ID: NCT03370692). There was no specific funding except an ESICM award received by HF. 


\section{Participants}

Only emergency (acute) ICU admissions in patients $\geq 80$ years of age were eligible. All reasons for acute ICU admissions were accepted.

\section{Data collection}

\section{Data collection at admission}

For each eligible patient, demographic data were collected: age, sex, place of living before admission to the hospital, and reason for admission according to a predefined list (ESM4).

Second, the study collected mandatory data on the patient's geriatric conditions prior to this hospital admission, including the clinical frailty scale (CFS) [10]. For the assessment of frailty, we defined the frailty level present before hospital admission and not affected by the acute illness. The information necessary to perform this assessment were given by patients or proxy or patient records, and the assessor's profession was reported. The Clinical Frailty Scale visual and with simple description were used with permission (ESM5) [10]. The scale is composed of 9 classes from very fit to terminally ill. Prefrail patients have a CFS of 4, while frail patients have a CFS of 5 or above. We also recorded Katz activities of daily living (Katz ADL) (ESM6) [11] with ADL score $\leq 4$ defining disability. Short form of Informant Questionnaire on Cognitive Decline in the Elderly (IQCODE) [12] (ESM7) was used. The information to calculate the IQCODE was given by caregivers with intimate knowledge of the patient for the past 10 years. We defined cognitive decline as an IQCODE $\geq 3.5$ [13]. Comorbidity and polypharmacy score (CPS) were calculated [14]. A CPS above 15 was considered as high.

\section{Data collection of variables during ICU admission}

Within the first $24 \mathrm{~h}$ of ICU admission the sequential organ failure assessment (SOFA) score was calculated [15]. The total SOFA score on admission was calculated using an online calculator in the eCRF. Length of ICU stay (LOS) was recorded as the number of hours between admission and discharge and latter converted to days in the analysis. Any period on non-invasive, invasive (with endotracheal intubation or tracheotomy) mechanical ventilation, use of vasoactive drugs and renal replacement therapy was registered with start (ICU day) and duration of the treatment (in hours).

Limitation of life sustaining therapies (LST) such as withholding or withdrawing life-supporting treatments was documented as performed and on which ICU day, or if not performed [16].

Outcome was measured as survival in the ICU and 30 days after ICU admission with information on the day of death after ICU admission. Information source for vital status at day 30 was documented.

The Case Record Form and database were hosted on a secure server located on the campus of Aarhus University, Denmark.

\section{Bias}

The ICUs were asked to include all acutely admitted, consecutive patients irrespective of the estimated duration of ICU stay.

\section{Study size}

We had no formal calculation in this purely observational study. We estimated a 30 -day mortality of $40 \%$ in a similar population [17].

\section{Statistical analysis}

Baseline characteristics of patients were analyzed as frequencies and percentages for categorical variables and as medians and interquartile ranges (IQRs) for continuous variables.

Principal Component Analysis (PCA) was used to represent the variation present in the dataset and show association between geriatric and severity variables (age, SOFA score, CPS, IQ code, Katz's scale and clinical frailty scale). For visual analysis, two-dimensional projection of the sample was constructed having the axes (principal components, PC) as the factors. Each PC is a linear combination of the original variables (that retain some correlation among each other) and PCs are orthogonal to each other.

The crude overall survival at 30 days was estimated by the Kaplan-Meier method and compared using a logrank test. We used multiple imputations for participants with missing data, using predictive mean matching for continuous variables, logistic regression for binary data, and polynomial regression for (unordered) categorical data. The cumulative baseline hazard was approximated by the Nelson-Aalen estimator and included in the imputation model. Five imputations were drawn.

Multivariable analyses were performed using the Cox proportional hazards model for overall survival at 30 days. All patients' characteristics listed in the CRF were included in our models including LST limitation. We used mean Akaike's information criterion (AIC) across imputations to evaluate the goodness of fit of our models. AIC $=-2 \log$ likelihood $+2 \mathrm{p}$, where $\mathrm{p}$ is the number of parameters [18]. Models with lower AIC are interpreted as models that best fit the data. Last, we included limitation decisions as a time-dependent variable to test whether geriatric parameters kept their prognostic value. Hazard ratio (HR) given by the Cox model 
describe the relative risk of death based on comparison of event rates in different groups. HR gives the change in risk of death per each unit increase for continuous variables and for one specific category versus a reference category for categorical variables. HR $>1$ suggests an increase in the risk of death, $H R<1$ suggest a decrease in the risk of death. A Cox model was used to analyze treatment limitation as a time to event variable.

Adjusted survival curves were produced using an inverse probability-weighted Kaplan-Meier estimation [19]. Significance was tested using a Cox regression model weighted by the same weights (inverse probability-weighted Cox). Inter-rater variability for assessing Clinical Frailty Scale was analyzed with Med-Calc for Windows 15.0 (MedCalc Software, Ostend, Belgium) and presented as Weighted kappa [20]. All analyses were performed by AB with R software, version 3.2.2 (R Foundation for Statistical Computing) (packages FactorMineR and missMDA for PCA, MICE for multiple imputations, survival for survival analysis, ipw for inverse-probability weighting, rms for adjusted survival curves).

\section{Results \\ Participants}

We included 3920 patients (median age 84 years) from 22 countries and 242 ICUs. Most patients lived at home without help $(72.8 \%$,) or with care-givers $(11.1 \%)$ before being admitted to the hospital. Admissions related to respiratory and/or circulatory failures and sepsis (as defined by sepsis 3 criteria) accounted for $63.2 \%$ of the total while emergency surgery represented $13.8 \%$ of the total admissions. The patients were severely ill as evidenced by a median SOFA score of 6 (IQR 4-9) (Table 1). Most patients had at least one organ support (Table 2). The median ICU LOS was 3.9 days (IQR: $1.83-8$ ).

No difference was found in patients' characteristics in ICUs with a recruitment period above vs. below the median of 60 days (ESM8) ruling out possible bias due to different recruitment times. Recruitment per ICU was excellent (ESM9) but patients included in countries with no need for informed consent were sicker with a SOFA score almost two points higher (ESM10).

The geriatric syndromes (Tables 1,3 ) were as follows: Median (IQR): CFS: 4 (3-6) with only 17 missing values. Information to assess CFS was given by the patient in $29.7 \%(1159 / 3901)$ and by the family in $51.7 \%$ (2016/3901). The professional assessor was an ICU physician $(59.8 \%, 2335 / 3901)$, an ICU nurse (13.7\%, 535/3901) or research staff $(23.7 \%, 925 / 3901)$. CPS values were similar when measured by different assessors (ESM11). The CFS was measured by two different raters in 1924 individuals. The weighted Kappa was 0.85 (95\%CI $0.84-$ 0.87) which is excellent (ESM12).

Frailty $(\mathrm{CFS} \geq 5)$ was present in $40.2 \%(1568 / 3903)$. IQCODE was 3.19 (3-3.69) with 940/3920 (24\%) missing values. Patients with missing values of IQCODE were different from patients with documented IQCODE (ESM123). IQCODE above 3.5 indicating a cognitive decline was observed in $30.2 \%$. Katz ADL was 6 (4-6) with $447 / 3920$ (11.4\%) missing values. An ADL of 4 or less, as a marker of functional decline was observed in $27.7 \%$ (962/3473). Comorbidity and polypharmacy score (CPS) was 10 (7-14) with 8/3920 (0.2\%) missing values. A CPS above 15 was present in $17.7 \%$ (693/3912) of the patients.

\section{Outcome data}

LST limitations were documented in 34.4\% (1332/3872) including withholding in $29.4 \%(1140 / 3872)$ of patients with a decision made at day 1 (IQR 1-4) and treatment withdrawal (with or without prior withholding) in $14 \%$ (545/3872) with a median decision time of 4 days (IQR 2-7) after ICU admission. Patients with LST limitation were frailer and more severely ill compared to patients with no LST limitation (Table 4). The multivariable analysis identified age, habitat, SOFA score, CPS and CFS as independent factors predicting decision to limit LST (Table 5).

The ICU and 30-day vital status were, respectively, available for $3900 / 3920(99.9 \%)$ and $3841 / 3920$ (99.4\%) patients. The vital status was assessed by checking the hospital records $(81.4 \%, 2780 / 3415)$, direct contact with the patient $(12.3 \%, 420 / 3415)$ or checking a national registry $(3.3 \%, 111 / 3415)$.

The overall proportion of patients surviving ICU was $72.5 \%$ (2828/3900). Survival after ICU admission was $96.3 \%$ at day one (95.7-96.9), $74.2 \%(72.8-75.6)$ at day 10 , $65.9 \%(64.5-67.5)$ at day 20 and $61.2 \%(59.7-62.7)$ at day 30.

\section{Predictive factors for 30-day survival}

In our PCA analysis the first two PC explain as much as $56.79 \%$ of the total variation in the sample; the analysis was restricted to these first two dimensions. PC1 retained $39 \%$ of data variation and differentiates the individuals according to Katz ADL, Clinical Frailty Scale and IQCODE. Similarly, PC2 explained another $18 \%$ of variability in the original data and separates the individuals based on severity (SOFA) and age. Figure 1 represents the projection of variables on the factor-plane and shows correlation between the three geriatric syndromes IQ code, Katz ADL and Clinical Frailty Scale. Except for 
Table 1 Patients characteristics

\begin{tabular}{|c|c|c|c|c|c|}
\hline Variables & Categories & All & Survivors & Non survivors & $p$-value \\
\hline & $\mathrm{N}$ & 3920 & 2327 & 1514 & \\
\hline Age & Median (range) (IQR) & 84 (range: $80-104)(81-87)$ & 84 (range 80-104) (81-87) & 84 (range 80-98) (82-87) & 0.04 \\
\hline \multirow[t]{2}{*}{ Gender } & Male & $2089(53.3 \%)$ & $1210(52 \%)$ & $836(55.2 \%)$ & \multirow[t]{2}{*}{0.06} \\
\hline & Female & $1831(46.7 \%)$ & $1117(48 \%)$ & $678(44.8 \%)$ & \\
\hline \multirow[t]{6}{*}{ Place of living } & $\begin{array}{l}\text { Own home (including if with } \\
\text { spouse) }\end{array}$ & $2852(72.8 \%)$ & $1774(76.3 \%)$ & $1031(68.1 \%)$ & \multirow[t]{6}{*}{$<0.0001$} \\
\hline & $\begin{array}{l}\text { Other home with family or } \\
\text { caregivers }\end{array}$ & $434(11.1 \%)$ & $228(9.8 \%)$ & $191(12.6 \%)$ & \\
\hline & Nursing home & $210(5.4 \%)$ & $112(4.8 \%)$ & $96(6.3 \%)$ & \\
\hline & Hospital ward & $361(9.2 \%)$ & $179(7.7 \%)$ & $174(11.5 \%)$ & \\
\hline & Other & $35(0.9 \%)$ & $22(0.9 \%)$ & $11(0.7 \%)$ & \\
\hline & Unknown & $27(0.7 \%)$ & $11(0.5 \%)$ & $11(0.7 \%)$ & \\
\hline \multirow[t]{11}{*}{ Reason for admission } & Respiratory failure & $944(24.1 \%)$ & $583(25.1 \%)$ & $343(22.7 \%)$ & \multirow[t]{11}{*}{$<0.0001$} \\
\hline & Circulatory failure & $541(13.8 \%)$ & $303(13 \%)$ & $228(15.1 \%)$ & \\
\hline & $\begin{array}{l}\text { Combined respiratory/circulatory } \\
\text { failure }\end{array}$ & $449(11.5 \%)$ & $186(8 \%)$ & $253(16.7 \%)$ & \\
\hline & Sepsis (according to Sepsis3) & $539(13.8 \%)$ & $287(12.3 \%)$ & $239(15.8 \%)$ & \\
\hline & Multitrauma without head injury & $87(2.2 \%)$ & $58(2.5 \%)$ & $27(1.8 \%)$ & \\
\hline & Multitrauma with head injury & $75(1.9 \%)$ & $35(1.5 \%)$ & $37(2.4 \%)$ & \\
\hline & Isolated head injury & $71(1.8 \%)$ & $33(1.4 \%)$ & $38(2.5 \%)$ & \\
\hline & Intoxication & $23(0.6 \%)$ & $17(0.7 \%)$ & $6(0.4 \%)$ & \\
\hline & Non-traumatic cerebral pathology & $190(4.8 \%)$ & $103(4.4 \%)$ & $84(5.5 \%)$ & \\
\hline & Emergency surgery & $541(13.8 \%)$ & $369(15.9 \%)$ & $163(10.8 \%)$ & \\
\hline & Other causes & $459(11.7 \%)$ & $352(15.1 \%)$ & $96(6.3 \%)$ & \\
\hline SOFA & Median (range) (IQR) & 6 (range: 0-20) (4-9) & 5 (range $0-18)(3-8)$ & 8 (range $0-20)(5-11)$ & $<0.0001$ \\
\hline CFS & Median (range) (IQR) & 4 (range: 1-9) (3-6) & 4 (range 1-9) (3-5) & 4 (range 1-9) (3-6) & $<0.0001$ \\
\hline IQ Code & Median (range) (IQR) & 3.19 (range: 1-5) (3-3.69) & 3.19 (range 1-5) (3-3.56) & 3.31 (range 1-5) (3-4) & $<0.0001$ \\
\hline ADL (Katz) & Median (range) (IQR) & 6 (range: 0-6) (4-6) & 6 (range 0-6) (5-6) & 6 (range 0-6) (3-6) & $<0.0001$ \\
\hline Comorbidities & Median (range) (IQR) & 4 (range: $0-20)(3-6)$ & 4 (range $0-20)(3-5)$ & 4 (range $0-20)(3-6)$ & 0.013 \\
\hline Drugs taken daily & Median (range) (IQR) & 6 (range: 0-26) (4-9) & 6 (range 0-21) (4-9) & 6 (range 0-26) (4-9) & 0.17 \\
\hline CPS & Median (range) (IQR) & 10 (range: 0-36) (7-14) & 10 (range 0-36) (7-14) & 11 (range 0-35) (7-14) & 0.05 \\
\hline
\end{tabular}

Vital status was assessed 1 month after ICU admission. 79 patients had no vital status reported at 1 month

SOFA sequential organ failure assessment, CFS clinical frailty scale, IQCODE informant questionnaire on cognitive decline in the elderly, $A D L$ activity of daily living, CPS Co-morbidity and Polypharmacy score

CPS, each geriatric syndrome had impact on 1-month survival (Fig. 2).

The multivariable analysis identified the usual predictors of 30-day outcome (HR; 95\% CI): Age (increase in risk of death per 1 year increase): $1.02(1-1.03, p=0.01)$, ICU admission diagnosis, SOFA (increase in risk of death per one-point increase): $1.15(1.14-1.17, p<0.0001)$ and CFS (increase in risk of death per one point increase): 1.1 $(1.05-1.15, p<0.001)$. The model including all geriatric parameters did not perform better than the model with CFS only (Table 6). The CPS was not independently associated with 30-day outcome. When including limitation decision as a time-dependent variable in the model, CFS still has a prognostic impact on survival with an increase in the risk of death per each unit increase of CFS of 1.08 $(1.05-1.12, p<0.001)$ (Table 7).

\section{Discussion}

In the ICU community there is a growing need for evidence and guidelines to ease the decision-making process for an informed ICU admission in the very old including ICU triage, and this should be supported by best available evidence [21]. In that perspective, this large prospective study of non-scheduled, acute ICU admissions provides important information.

We confirmed that 30-day survival is very low $(61.2 \%)$ in unselected patients 80 years or older who are acutely admitted to the ICU. Age-related symptoms as frailty, 
Table 2 ICU stay characteristics

\begin{tabular}{|c|c|c|c|c|c|}
\hline Variables & Categories & All & Survivors & Non survivors & $p$-value \\
\hline & $\mathrm{N}$ & 3920 & 2327 & 1514 & \\
\hline Intubation & Yes & 1953 (49.9\%) & $939(40.4 \%)$ & $974(64.5 \%)$ & $<0.0001$ \\
\hline Tracheostomy & Yes & $264(6.8 \%)$ & $168(7.2 \%)$ & $90(6 \%)$ & 0.14 \\
\hline Non invasive ventilation & Yes & $903(23.1 \%)$ & $547(23.6 \%)$ & $342(22.6 \%)$ & 0.51 \\
\hline Vaso active drugs & Yes & $2329(59.5 \%)$ & $1169(50.3 \%)$ & $1114(73.6 \%)$ & $<0.0001$ \\
\hline Renal replacement therapy & Yes & $429(11 \%)$ & $163(7 \%)$ & $259(17.1 \%)$ & $<0.0001$ \\
\hline Withholding of treatment & Yes & $1140(29.4 \%)$ & $390(16.9 \%)$ & $738(49.2 \%)$ & $<0.0001$ \\
\hline Withdrawing of treatment & Yes & $545(14 \%)$ & $27(1.2 \%)$ & $517(34.4 \%)$ & $<0.0001$ \\
\hline ICU LOS in days & Median (range) (IQR) & $3.88(0.04-30)(1.83-8)$ & $3.67(0.04-30)(1.92-7.71)$ & $4(0.04-30)(1.54-8.46)$ & 0.75 \\
\hline \multirow[t]{2}{*}{ ICU survival } & Missing & 13 & 10 & 3 & \\
\hline & Alive & $2828(72.5 \%)$ & 2285 (98.6\%) & $471(31.2 \%)$ & $<0.0001$ \\
\hline \multirow[t]{2}{*}{30 days' survival } & Missing & 79 & & & \\
\hline & Alive & $2346(61.1 \%)$ & & & \\
\hline Day of death & Median (range) (IQR) & & & $7(0-30)(3-14)$ & \\
\hline
\end{tabular}

Non-survivors are defined by 30-day mortality

Table 3 Scores assessed as categories

\begin{tabular}{|c|c|c|c|c|c|}
\hline Variables & Categories & All & Survivors & Non survivors & $p$-value \\
\hline \multirow[t]{3}{*}{ CFS } & Fit (CFS 1-3) & $1544(39.6 \%)$ & $1011(43.5 \%)$ & $509(33.9 \%)$ & \multirow[t]{3}{*}{$<0.0001$} \\
\hline & Vulnerable (CFS 4) & 791 (20.3\%) & $483(20.8 \%)$ & $287(19.1 \%)$ & \\
\hline & Frail (CFS 5-8) & $1568(40.2 \%)$ & $830(35.7 \%)$ & 704 (46.9\%) & \\
\hline \multirow[t]{4}{*}{ IQCODE categories } & $<3$ & $178(6 \%)$ & $125(6.3 \%)$ & $48(5.1 \%)$ & \multirow[t]{4}{*}{$<0.0001$} \\
\hline & 3 & 709 (23.8\%) & $483(24.5 \%)$ & $212(22.3 \%)$ & \\
\hline & $>3-3.5$ & $1194(40.1 \%)$ & $859(43.6 \%)$ & $316(33.3 \%)$ & \\
\hline & $>3.5$ & $899(30.2 \%)$ & $505(25.6 \%)$ & $373(39.3 \%)$ & \\
\hline \multirow[t]{3}{*}{ CPS categories } & $0-9$ & $1697(43.4 \%)$ & $1024(44 \%)$ & $644(42.6 \%)$ & \multirow[t]{3}{*}{0.12} \\
\hline & $10-15$ & $1522(38.9 \%)$ & $913(39.3 \%)$ & $575(38.1 \%)$ & \\
\hline & $>15$ & $693(17.7 \%)$ & $389(16.7 \%)$ & 292 (19.3\%) & \\
\hline \multirow[t]{3}{*}{ KATZ categories } & $0-4$ & $962(27.7 \%)$ & $500(22.6 \%)$ & $441(36.8 \%)$ & \multirow[t]{3}{*}{$<0.0001$} \\
\hline & 5 & 440 (12.7\%) & 295 (13.3\%) & $135(11.3 \%)$ & \\
\hline & 6 & $2071(59.6 \%)$ & 1417 (64.1\%) & $623(52 \%)$ & \\
\hline \multirow[t]{3}{*}{ SOFA categories } & SOFA 0-5 & $1741(44.5 \%)$ & 1304 (56.2\%) & $410(27.1 \%)$ & \multirow[t]{3}{*}{$<0.0001$} \\
\hline & $6-9$ & $1286(32.9 \%)$ & 699 (30.1\%) & $555(36.7 \%)$ & \\
\hline & $>10$ & $882(22.6 \%)$ & $317(13.7 \%)$ & $547(36.2 \%)$ & \\
\hline
\end{tabular}

cognitive decline and disability were strongly associated with 30-day mortality and were more important than age alone. Comorbidity and polypharmacy, however, had no predictive value when measured as the CPS. Interestingly, the addition of cognitive impairment and disability to the prognostic analysis did not increase prognostic value compared with the model with frailty alone. The CFS was reported in $99.5 \%$ of the cases and the interrater reproducibility was very good confirming that this tool is robust and easy to use.

In a previous prospective study in Europe, frailty was found to be present in $46 \%$ of acute admitted elderly
ICU patients [4] and was closely related to both ICU and 30-day mortality. In the present study, frailty remained independently associated with both ICU and 30 days mortality, and this strengthens its importance in preICU assessment. Frailty affects several important body functions like the endocrine system, brain, muscular and immune function, all very important in the ICU context, and was recently discussed in a clinical review [22]. The link between frailty and health-related quality of life was documented in a prospective Canadian study [23]. Frail patients were found to report reduced quality of life both in the physical and mental subset of EuroQol Health 
Table 4 Patient characteristics according to decision to limit life sustaining treatment: withholding and/or withdrawing

\begin{tabular}{|c|c|c|c|c|c|}
\hline Variables & Categories & All & No limitation & Withdraw and/or withhold & $p$-value \\
\hline & N & 3920 & 2540 & 1332 & \\
\hline Age & Median (range) (IQR) & $\begin{array}{l}84 \text { (range: } 80-104) \text { (IQR: } \\
81-87 \text { ) }\end{array}$ & 83 (range 80-100) (IQR 81-86) & 84 (range 80-99) (IQR 82-87) & $<0.0001$ \\
\hline \multirow[t]{2}{*}{ SOFA } & Missing & 11 & 3 & 6 & \\
\hline & Median (range) (IQR) & 6 (range: 0-20) (IQR: 4-9) & 6 (range 0-20) (IQR 3-9) & 7 (range 0-19) (IQR 5-10) & $<0.0001$ \\
\hline \multirow[t]{2}{*}{ CFS } & Missing & 17 & 7 & 9 & \\
\hline & Median (range) (IQR) & 4 (range: 1-9) (IQR: 3-6) & 4 (range 1-9) (IQR 3-5) & 4 (range 1-9) (IQR 3-6) & $<0.0001$ \\
\hline \multirow[t]{2}{*}{ IQ Code } & Missing & 940 & 504 & 416 & \\
\hline & Median (range) (IQR) & 3.19 (range: 1-5) (IQR: 3-3.69) & 3.19 (range 1-5) (IQR 3-3.57) & $\begin{array}{l}3.31 \text { (range 1-5) (IQR } \\
3.06-3.88)\end{array}$ & $<0.0001$ \\
\hline \multirow[t]{2}{*}{ Katz } & Missing & 447 & 219 & 215 & \\
\hline & Median (range) (IQR) & 6 (range: 0-6) (IQR: 4-6) & 6 (range 0-6) (IQR 5-6) & 6 (range 0-6) (IQR 4-6) & $<0.0001$ \\
\hline \multirow[t]{2}{*}{ Comorbidities } & Missing & 7 & 1 & 2 & \\
\hline & Median (range) (IQR) & 4 (range: 0-20) (IQR: 3-6) & 4 (range 0-20) (IQR 3-5) & 4 (range 0-20) (IQR 3-6) & 0.005 \\
\hline \multirow[t]{2}{*}{ Drugs daily } & Missing & 8 & 1 & 2 & \\
\hline & Median (range) (IQR) & 6 (range: 0-26) (IQR: 4-9) & 6 (range 0-21) (IQR 4-8) & 7 (range 0-26) (IQR 4-9) & $<0.0001$ \\
\hline \multirow[t]{2}{*}{ CPS } & Missing & 8 & 1 & 2 & \\
\hline & Median (range) (IQR) & 10 (range: 0-36) (IQR: 7-14) & 10 (range 0-36) (IQR 7-14) & 11 (range 0-35) (IQR 8-5) & $<0.0001$ \\
\hline \multirow{2}{*}{$\begin{array}{l}\text { ICU LOS in days (all } \\
\text { patients alive/ } \\
\text { dead) }\end{array}$} & Missing & 11 & 3 & 1 & \\
\hline & Median (range) (IQR) & $\begin{array}{l}3.88 \text { (range: } 0.04-120) \text { (IQR: } \\
1.83-8)\end{array}$ & $\begin{array}{l}3.96 \text { (range } 0.04-120)(\mathrm{IQR} \\
1.96-8)\end{array}$ & $\begin{array}{l}3.67 \text { (range 0.04-85.5) (IQR } \\
\quad 1.54-7.85)\end{array}$ & 0.03 \\
\hline
\end{tabular}

$N=48$ patients with missing information on LST limitation (WH/WD)

Table 5 Multivariate analysis of treatment limitation (Cox model analyzing treatment limitation as a time to event variable)

\begin{tabular}{|c|c|c|c|}
\hline Variables & Categories & $\mathrm{HR}(95 \% \mathrm{Cl})$ & $p$-value \\
\hline Age & One-point increase & $1.04(95 \%$ Cl 1.03-1.06) & $<0.00001$ \\
\hline Habitat (ref = not home) & Own home & $1.27(95 \%$ Cl 1.12-1.45) & 0.0004 \\
\hline Gender (ref = male) & Female & $1.08(95 \%$ Cl 0.97-1.21) & 0.17 \\
\hline \multirow{7}{*}{$\begin{array}{l}\text { Reason for admission (ref = circulatory } \\
\text { failure) }\end{array}$} & Combined respiratory/circulatory failure & $0.9(95 \%$ Cl 0.7-1.11) & 0.32 \\
\hline & Emergency surgery & $0.67(95 \% \mathrm{Cl} 0.5-0.83)$ & 0.0003 \\
\hline & Multitrauma with head injury & $0.92(95 \%$ Cl 0.-1.41) & 0.70 \\
\hline & Multitrauma without head injury & $0.77(95 \%$ Cl 0.-1.18) & 0.23 \\
\hline & Other & $0.8(95 \%$ Cl 0.6-0.97) & 0.02 \\
\hline & Respiratory failure & 1 (95\% Cl 0.8-1.19) & 0.96 \\
\hline & Sepsis (according to Sepsis3) & $0.92(95 \%$ Cl 0.75-1.12) & 0.40 \\
\hline SOFA & One-point increase & 1.07 (95\% Cl 1.05-1.09) & $<0.00001$ \\
\hline CPS & One-point increase & $1.01(95 \% \mathrm{Cl} 1-1.02)$ & 0.009 \\
\hline CFS & One-point increase & $1.11(95 \%$ Cl 1.08-1.15) & $<0.00001$ \\
\hline
\end{tabular}

Questionnaire and in the SF-12. The use of the CFS has probably expanded lately, and different acute care settings find it useful to evaluate elderly patients in such a quick manner, even without patient contribution [24-26], making it of particular interest in the unresponsive or unconscious patient. There is also an emerging line of research trying to link frailty with delirium. Future studies are required to investigate the possible link between these two factors on ICU survival [27].

Cognitive decline has been found to affect mortality in many clinical settings [28, 29] and several methods are used to diagnose and assess the severity of cognitive decline and dementia. Most of these tests require active patient involvement and are, for obvious reasons, not 


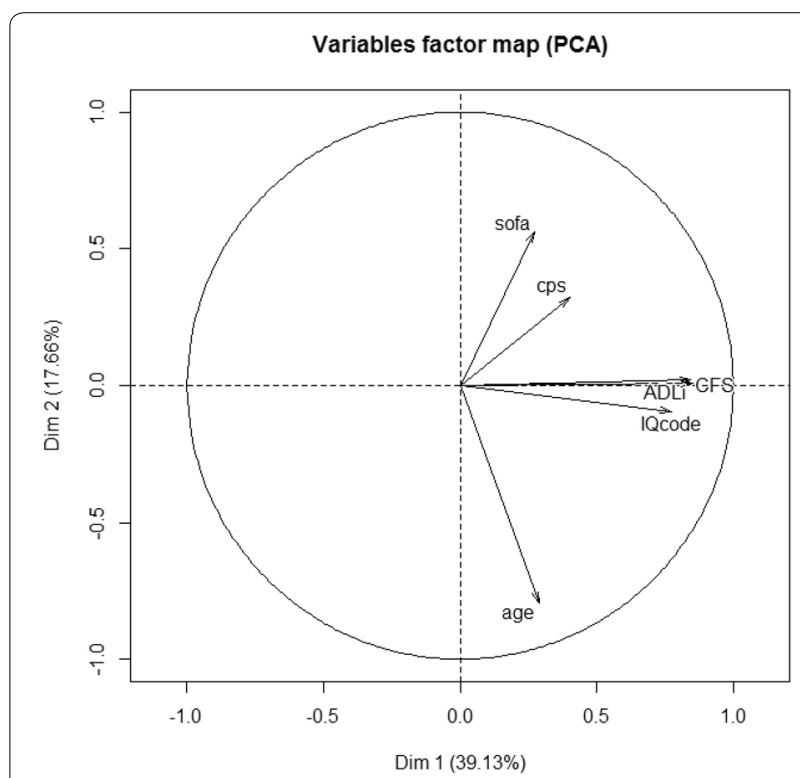

Fig. 1 Principal component analysis (PCA). Two-dimensional projection of the sample was constructed having the axes (principal components, PC) as the factors. Each PC is a linear combination of the original variables and PCs are orthogonal to each other. The angles between the vectors tell us how variables correlate with one another: when two vectors are close, forming a small angle, the two variables they represent are positively correlated. If they meet each other at $90^{\circ}$, they are not likely to be correlated and when they diverge and form a large angle (close to $180^{\circ}$ ), they are negatively correlated. The length of the vector shows how much weight a specific variable has on each principal component

applicable to patients who are acutely admitted to the ICU. Hence, we must rely on information from someone close to the patient in order to approach cognitive function if there is no clear evidence from patient records. The IQCODE was developed as a response to such demand [30] and has been used frequently as a simple screening tool based on information from caregivers. The IQCODE has been analyzed in a Cochrane review with regard to its accuracy in finding patients with dementia [13]. A threshold of 3.3 had 0.83 sensitivity and 0.80 specificity while a threshold of 3.5 had 0.82 sensitivity and 0.84 specificity. Studies where IQCODE has been applied prior to ICU admission are scarce. An early study of IQCODE compared with Modified Blessed Dementia Rating Scale (MBDRS) was performed in 130 ICU patients $\geq 65$ years [31]. They found that an IQCODE $>3.3$ was present in $31 \%$ of their patients. Using the same threshold, we found $44 \%$ having an IQCODE > 3.3, and the higher percentage probably mirrors the older age group in our study. With a threshold of 3.5; the prevalence of cognitive impairment was $30.2 \%$. In a more recent study from Spain, ICU patients were prospectively studied with data on cognition (IQCODE), activity of daily life, comorbidity and a full geriatric assessment in addition to disease severity scores [32]. They found parameters related to quality of life and functional status to be independently correlated with mortality, but not cognitive decline. However, most of their patients had IQCODE values within the normal range. Although IQCODE did not increase the predictive value when added to frailty, it was shown to have impact on 30-day outcome. It is possible that other more specific measures on cognitive decline would have performed better, but such may be difficult to implement in an acute setting. Even the IQCODE proved the most difficult measure to obtain in our cohort with $24 \%$ missing data.

The CPS score is a simple score, which measures the impact of comorbidity by adding the number of comorbidities to the number of daily drugs [33]. Different thresholds have been used, but often a CPS score of $<8$ has been considered to be categorized as minor, 8-14 as moderate and $\geq 15$ as major comorbidity. In our cohort the median CPS value was 10 , and $22 \%$ had a $\mathrm{CPS} \geq 15$. We have not found data from its previous use in ICU patients, but using the CPS in geriatric trauma (age $\geq 65$ years), the investigators found CPS to predict mortality better than the more traditional Charlson Comorbidity Index (CCI) [34]. Other studies have found the CPS to predict hospital mortality and readmissions $[35,36]$ and to predict in hospital complications in older burn patients [37]. However, in our study this score had no impact on outcome prediction.

Our main aim was to document the impact from the clinical situation present before ICU admission on outcome in very old ICU patients. Such knowledge could support the important clinical decision of pre-ICU triage: Will this patient benefit from being admitted to the ICU? [21]. Despite associations between the geriatric syndromes and outcome, we will probably not be able to answer this important question just by using evaluation tools and measurement. Often the patient is admitted to the ICU in order to observe response to initial treatment. Important information related to survival can also be found during the first $48-72 \mathrm{~h}$ in the ICU. Hence the degree of organ dysfunction and vital organ support could be highly relevant due to what frequently is called the "in ICU triage". Such an evaluation, formal or informal, often leads to treatment being withheld and/or withdrawn. As a matter of fact, LST limitations occurred in $34.4 \%$ of the patients. Severity (SOFA) and also frailty were independent factors predicting decision to limit LST. In the Ethicus- 2 study, LST limitations were documented in $13.1 \%$, but the patients were younger (median 70 years) and age was found to be one of the determinants for EOL decision [38].

In our study, some form of organ support was given in $80 \%$ of all ICU admissions, most often as ventilator 

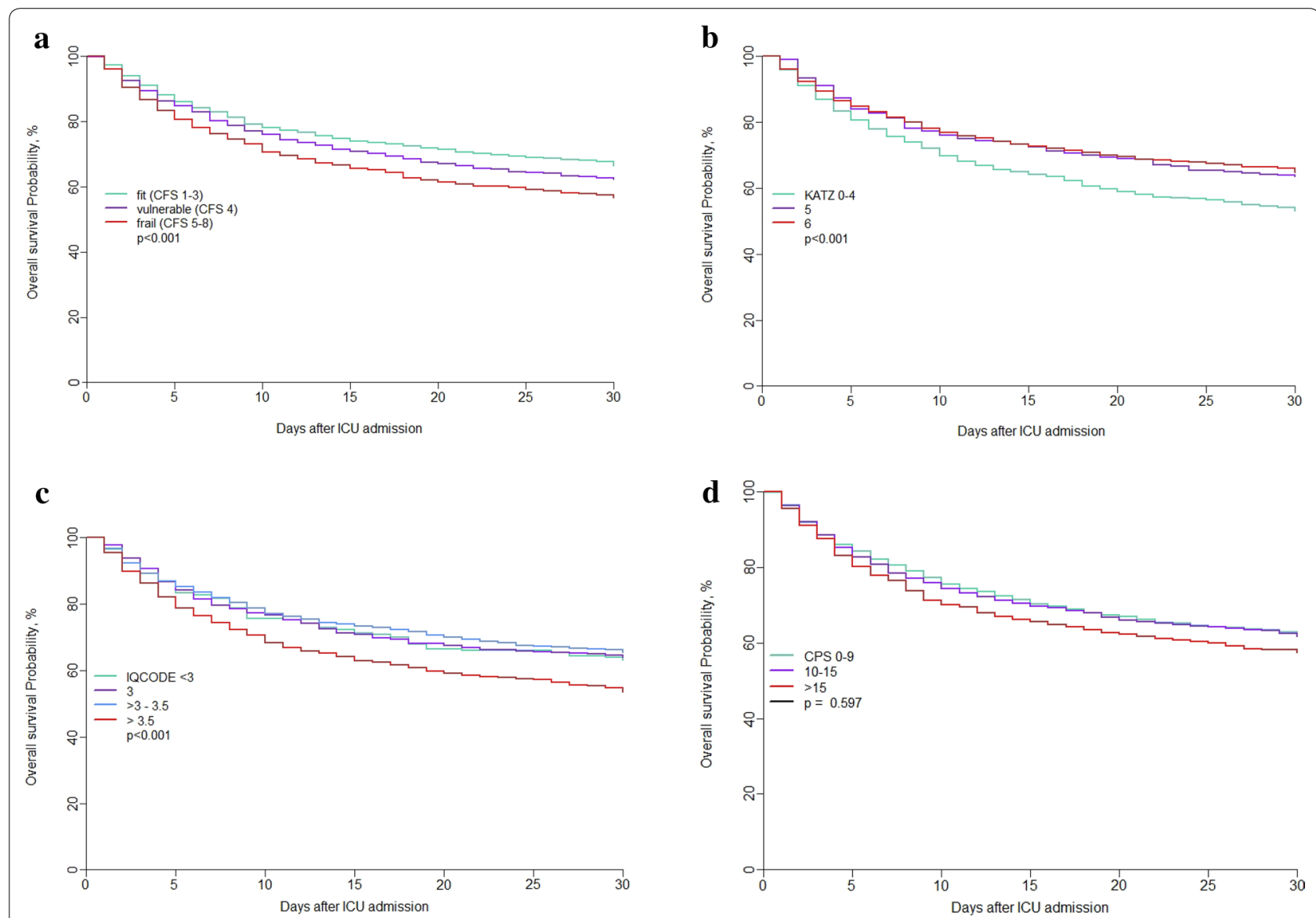

Fig. 2 Adjusted survival curves according to geriatric symptoms: Adjusted survival curves for geriatric variables were produced using an inverse probability-weighted Kaplan-Meier estimation [19]. Variables used to adjust the curves were age, gender, place of living, reason for ICU admission and SOFA score. Significance was tested using a Cox regression model weighted by the same weights (inverse probability-weighted Cox). a Survival curves according to CFS. b Survival curves according to Katz ADL. c Survival curves according to IQCODE. d Survival curves according to CPS

and cardiovascular support. This indicates that in most of the cases, there is no therapeutic limitation, and the very old ICU patients in our study were given active organ support when admitted to an ICU.

\section{Strengths and limitations}

The main strength of this study is the number of participants derived from several European countries, with different cultural and legal settings, and the prospective multicenter observation study design using the same definitions of the geriatric syndromes. Limitation of LST is common practice in most ICUs in Europe and contributes to the observed mortality. Patients with such decision differ from other patients (Table 4), but excluding those patients would introduce a bias to this "real life" observational study. When LST limitation was included in the multivariable model, CFS still has a prognostic impact on survival. The study was conducted within 1 year. Hence, we assume that trends in time do not influence the external validity. An unforeseen limitation was a huge delay in ethical and regulatory clearance in many countries caused by the General Data Protection Regulation (GDPR) introduced in all EU countries from May 2018. This made the actual recruitment period shorter for many ICUs. However, when comparing ICU with short versus long recruitment period, the patients' characteristics were very similar (see ESM 8). The estimated percentage of included patients to the potential candidates was 71.7\% (ESM 9), but patients' characteristics were different in countries with a need for informed consent compared to patients enrolled in countries with no-informed consent (ESM10). This study did not focus on pre-ICU triage, and hence we cannot exclude some selection bias, in particular given the high number of patients living in their own home prior to admission. ICU triage has been the focus of other studies [39]. There is only scarce evidence of the inter-rater variability of the CFS between the caregiver and the patient when the 
Table 6 Multivariable analysis (Cox regression analysis)

\begin{tabular}{|c|c|c|c|c|c|c|c|c|c|}
\hline \multirow[t]{2}{*}{ Variables } & \multirow[t]{2}{*}{ Categories } & \multicolumn{2}{|l|}{ ALL covariates } & \multicolumn{2}{|l|}{ CFS } & \multicolumn{2}{|l|}{ Katz } & \multicolumn{2}{|l|}{ IQ code } \\
\hline & & $\mathrm{HR}(95 \% \mathrm{Cl})$ & $p$-value & $\mathrm{HR}(95 \% \mathrm{Cl})$ & $p$-value & HR $(95 \% \mathrm{Cl})$ & $p$-value & HR $(95 \% \mathrm{Cl})$ & $p$-value \\
\hline Age & One-point increase & $1.02(1-1.03)$ & 0.01 & $\begin{array}{l}1.02(1.01- \\
1.03)\end{array}$ & 0.006 & $\begin{array}{l}1.02(1.01- \\
1.04)\end{array}$ & 0.002 & $\begin{array}{l}1.02(1.01- \\
1.04)\end{array}$ & 0.003 \\
\hline $\begin{array}{l}\text { Habitat } \\
\text { (ref = not } \\
\text { home) }\end{array}$ & Own home & $1.01(0.9-1.14)$ & 0.83 & $1(0.89-1.12)$ & 0.96 & $0.98(0.87-1.1)$ & 0.73 & $\begin{array}{l}0.95(0.84- \\
1.08)\end{array}$ & 0.43 \\
\hline $\begin{array}{l}\text { Gender } \\
\quad(\text { ref = male) }\end{array}$ & Female & $\begin{array}{l}0.98(0.88- \\
1.09)\end{array}$ & 0.68 & $\begin{array}{l}0.98(0.88- \\
1.09)\end{array}$ & 0.67 & $1(0.9-1.11)$ & 0.96 & $\begin{array}{l}1.01(0.91- \\
1.13)\end{array}$ & 0.79 \\
\hline $\begin{array}{l}\text { Reason for } \\
\text { admission }\end{array}$ & $\begin{array}{l}\text { Combined respira- } \\
\text { tory/circulatory } \\
\text { failure }\end{array}$ & $\begin{array}{l}1.07(0.89- \\
1.29)\end{array}$ & 0.46 & $\begin{array}{l}1.07(0.89- \\
1.29)\end{array}$ & 0.46 & $\begin{array}{l}1.09(0.91- \\
1.31)\end{array}$ & 0.34 & $\begin{array}{l}1.09(0.91- \\
1.31)\end{array}$ & 0.37 \\
\hline \multirow[t]{6}{*}{$\begin{array}{l}\text { (Ref }=\text { circula- } \\
\text { tory failure) }\end{array}$} & Emergency surgery & $\begin{array}{l}0.64(0.52- \\
0.78)\end{array}$ & $<0.0001$ & $\begin{array}{l}0.64(0.52- \\
0.78)\end{array}$ & $<0.0001$ & $\begin{array}{l}0.64(0.52- \\
0.78)\end{array}$ & $<0.0001$ & $\begin{array}{l}0.63(0.51- \\
0.77)\end{array}$ & $<0.001$ \\
\hline & $\begin{array}{l}\text { Multitrauma w/wo } \\
\text { head injury }\end{array}$ & $\begin{array}{l}1.16(0.81- \\
1.64)\end{array}$ & 0.41 & $\begin{array}{l}1.15(0.81- \\
1.64)\end{array}$ & 0.42 & $1.12(0.79-1.59)$ & 0.51 & $\begin{array}{l}1.09(0.77- \\
1.54)\end{array}$ & 0.63 \\
\hline & $\begin{array}{l}\text { Multitrauma with- } \\
\text { out head injury }\end{array}$ & $\begin{array}{l}0.86(0.58- \\
1.29)\end{array}$ & 0.46 & $\begin{array}{l}0.87(0.58- \\
1.29)\end{array}$ & 0.48 & $\begin{array}{l}0.83(0.56- \\
1.23)\end{array}$ & 0.35 & $\begin{array}{l}0.78(0.53- \\
1.16)\end{array}$ & 0.23 \\
\hline & Other & $\begin{array}{l}0.81(0.67- \\
0.97)\end{array}$ & 0.025 & $\begin{array}{l}0.81(0.67- \\
0.98)\end{array}$ & 0.03 & $0.8(0.66-0.97)$ & 0.02 & $\begin{array}{l}0.79(0.66- \\
0.96)\end{array}$ & 0.016 \\
\hline & Respiratory failure & $\begin{array}{l}0.81(0.69- \\
0.96)\end{array}$ & 0.017 & $\begin{array}{l}0.82(0.69- \\
0.97)\end{array}$ & 0.02 & $\begin{array}{l}0.82(0.69- \\
0.98)\end{array}$ & 0.02 & $\begin{array}{l}0.82(0.69- \\
0.98)\end{array}$ & 0.03 \\
\hline & $\begin{array}{l}\text { Sepsis (according } \\
\text { to Sepsis3) }\end{array}$ & $\begin{array}{l}0.71(0.59- \\
0.86)\end{array}$ & 0.0003 & $0.71(0.59-0.86)$ & 0.0003 & $0.72(0.6-0.87)$ & 0.0005 & $0.71(0.59-0.86)$ & 0.0004 \\
\hline SOFA & One-point increase & $\begin{array}{l}1.15(1.14- \\
1.17)\end{array}$ & $<0.00001$ & $\begin{array}{l}1.15(1.14- \\
1.17)\end{array}$ & $<0.00001$ & $\begin{array}{l}1.15(1.14- \\
1.17)\end{array}$ & $<0.001$ & $1.15(1.14-1.17)$ & $<0.00001$ \\
\hline CPS & One-point increase & $1(0.99-1.01)$ & 0.75 & $1(0.99-1.01)$ & 0.74 & $1(0.99-1.01)$ & 0.65 & $1.01(1-1.02)$ & 0.28 \\
\hline CFS & One point increase & $1.1(1.05-1.15)$ & 0.0001 & $\begin{array}{l}1.12(1.09- \\
1.15)\end{array}$ & $<0.00001$ & & & & \\
\hline Katz & One point increase & $\begin{array}{l}0.98(0.94- \\
1.02)\end{array}$ & 0.40 & & & $0.93(0.9-0.95)$ & $<0.00001$ & & \\
\hline \multirow[t]{2}{*}{ IQ code } & One-point increase & $\begin{array}{l}1.03(0.91- \\
1.18)\end{array}$ & 0.63 & & & & & $\begin{array}{l}1.18(1.06- \\
1.31)\end{array}$ & 0.0029 \\
\hline & $\begin{array}{l}\text { Mean AIC across } \\
\text { imputations }\end{array}$ & $23,993.92$ & & $23,991.31$ & & $24,016.93$ & & $24,025.87$ & \\
\hline
\end{tabular}

HR gives the change in risk of death per each unit increase for continuous variables and for one specific category versus a reference category for categorical variables. $\mathrm{HR}>1$ suggests an increase in the risk of death, $\mathrm{HR}<1$ suggests a decrease in the risk of death

SOFA sequential organ failure assessment, CFS clinical frailty scale, IQCODE informant questionnaire on cognitive decline in the elderly, $A D L$ activity of daily living, CPS Co-morbidity and Polypharmacy score

AIC Akaike's information criterion. AIC was used across imputations to evaluate the goodness of fit of our models. AIC $=-2$ Log likelihood $+2 p$, where $p$ is the number of parameters

CFS is performed at the same time. However, one study concluded that CFS scores can be reliably assigned retrospectively [40] and another study, comparing CFS using different assessors, concluded that "CFS scores can be generated using medical chart review and can be reliably completed by ICU clinicians and research staff" [41]. Inter-rater was excellent in our study with a weighted kappa above 0.8 . The IQCODE was missing in $24 \%$ and was based on informant data collected in a life-threatening situation suggesting that it is not a good tool for critically ill patients.
Another limitation is the lack of other explanatory variables like individual socio-economic status, education and the absence of delirium evaluation on admission and during the ICU stay. We focused on mortality but other outcomes such as long-term ventilation, chronic critical illness and cognitive dysfunction which are patient-relevant outcomes should also be assessed in future studies.

\section{Conclusions}

We found that Clinical frailty scale alone was an independent prognostic factor for 1-month survival after ICU admission. Adding other geriatric syndromes and 
Table 7 Multivariable analysis including life-sustaining treatment limitation

\begin{tabular}{|c|c|c|c|}
\hline Variables & Categories & HR $(95 \% \mathrm{Cl})$ & $p$-value \\
\hline Age & One-point increase & $1(0.99-1.02)$ & 0.79 \\
\hline Habitat (ref = not home) & Own home & $0.96(0.85-1.08)$ & 0.47 \\
\hline Gender (ref = male) & Female & $0.94(0.84-1.04)$ & 0.24 \\
\hline \multirow{7}{*}{$\begin{array}{l}\text { Reason for admission (ref = circulatory } \\
\text { failure) }\end{array}$} & Combined respiratory/circulatory failure & $1.13(0.94-1.36)$ & 0.19 \\
\hline & Emergency surgery & $0.68(0.56-0.84)$ & 0.0003 \\
\hline & Multitrauma w/wo head injury & $1.21(0.85-1.73)$ & 0.28 \\
\hline & Multitrauma without head injury & $0.91(0.61-1.36)$ & 0.64 \\
\hline & Other & $0.88(0.73-1.06)$ & 0.18 \\
\hline & Respiratory failure & $0.82(0.69-0.97)$ & 0.021 \\
\hline & Sepsis (according to Sepsis3) & $0.67(0.55-0.81)$ & 0.0003 \\
\hline SOFA & One-point increase & $1.16(1.14-1.17)$ & $<0.0001$ \\
\hline CPS & One-point increase & $0.99(0.98-1)$ & 0.05 \\
\hline CFS & One-point increase & $1.08(1.05-1.12)$ & $<0.0001$ \\
\hline Withholding or withdrawal & Yes vs no & $4.25(3.8-4.74)$ & $<0.0001$ \\
\hline
\end{tabular}

scores did not improve the model. This is an important finding suggesting that collection of only one score is feasible in circumstances of rapid processing of the decision making to admit or refuse an old patient in ICU. Predicting the future, look at the past! [42].

\section{Electronic supplementary material}

The online version of this article (https://doi.org/10.1007/s00134-019-05853-1) contains supplementary material, which is available to authorized users.

\footnotetext{
Author details

1 Sorbonne Université, INSERM, Institut Pierre Louis d'Epidémiologie et de Santé Publique, Saint Antoine Hospital, AP-HP, Hôpital Saint-Antoine, service de réanimation, F75012 Paris, France. ${ }^{2}$ Department of Intensive Care Medicine, University Medical Center, University Utrecht, Utrecht, The Netherlands. ${ }^{3}$ AP-HP, Hôpital Saint-Antoine, service de réanimation, F75012 Paris, France. ${ }^{4}$ Research Lead Critical Care Directorate St George's Hospital, London, UK. ${ }^{5}$ St George's University Hospital, London, UK. ${ }^{6}$ Chair NAHP Section ESICM, Intensive Care Unit, Royal Devon \& Exeter NHS Foundation Trust, Exeter, UK. ${ }^{7}$ Intensive Care and Perioperative Medicine Division, Jagiellonian University Medical College, Kraków, Poland. ${ }^{8}$ Department of Intensive Care Medicine, CIBER Enfermedades Respiratorias, Sabadell and Critical Care Department, Corporacion Sanitaria Universitaria Parc Tauli, Autonomous University of BarceIona, Sagrado Corazon-General de Cataluña University Hospitals, Quiron Salud, Barcelona, Spain. ${ }^{9}$ Department of Rehabilitation Hospital Ancelle di Cremona Italy, Geriatric Research Group, Brescia, Italy. ${ }^{10}$ Department of Anaesthesia and Intensive Care, NTNU, Dep of Circulation and Medical Imaging, Ålesund Hospital, Trondheim, Ålesund, Norway. ${ }^{11}$ Intensive Care Unit General Hospital of Larissa Tsakal of Larissa, Larissa, Greece. ${ }^{12}$ Division of Cardiology, Pulmonology and Vascular Medicine, University Hospital Düsseldorf, Heinrich-HeineUniversity, Düsseldorf, Germany. ${ }^{13}$ Faculdade de Ciências Médicas de Lisboa (Nova Médical School), Unidade de Cuidados Intensivos Neurocríticos e Trauma. Hospital de São José, Centro Hospitalar Universitário de Lisboa Central, Lisbon, Portugal. ${ }^{14}$ Linkoping University Hospital, Linkoping, Sweden. ${ }^{15}$ Department of Intensive Care 1K12IC Ghent University Hospital, Ghent, Belgium. ${ }^{16}$ Department of Intensive Care Medicine, Inselspital, Universitätsspital, University of Bern, Bern, Switzerland. ${ }^{17}$ Department of Anesthesia and Intensive Care Medicine, Humanitas Clinical and Research Center - IRCCS, Via Alessandro Manzoni 56, 20089 Rozzano, MI, Italy. ${ }^{18}$ Department of Biomedical Sciences, Humanitas University, Pieve Emanuele, Rozzano, MI, Italy. ${ }^{19}$ Mater Misericordiae University Hospital, Dublin, Ireland. ${ }^{20}$ Division of Intensive Care and Emergency Medicine, Department of Internal Medicine, Medical
}

University Innsbruck, Innsbruck, Austria. ${ }^{21}$ European Wellness International, ICU, Luhansk, Ukraine. ${ }^{22}$ Alkhums Hospital, ICU, Tripoli, Libya. ${ }^{23}$ Department of Intensive Care, Aarhus University Hospital, Aarhus, Denmark. ${ }^{24}$ Dep. of Clinical Medicine, University of Bergen, Bergen, Norway. ${ }^{25}$ Department of Anaesthesia and Intensive Care, Haukeland University Hospital, Bergen, Norway.

\section{Acknowledgement}

This study was endorsed by the ESICM. Free support for running the electronic database and was granted from the dep. of Epidemiology, University of Aarhus, Denmark. Financial support for creation of the e-CRF and maintenance of the database was possible from a grant (open project support) by Western Health region in Norway) 2018 who also funded the participating Norwegian ICUs. DRC Ile de France and URC Est helped conducting VIP2 in France. The VIP2-study collaborators are listed in the ESM 1.

\section{Author contributions}

$B G, D D L, H F$ designed the study; AB performed the statistical analysis; JF run the database and the eCRF; $B G, D D L, H F, A B$ drafted the manuscript; $A M$ provided geriatric expertise in designing the protocol. All other authors were country coordinators and validated the manuscript.

\section{Compliance with ethical standards}

\section{Conflicts of interest}

Joerg C. Schefold declares that the Dept. of Intensive Care Medicine Bern has/ had research and/or development/consulting contracts with (full disclosure): Orion Corporation, Abbott Nutrition International, B. Braun Medical AG, CSEM SA, Edwards Lifesciences Services GmbH/SA, Kenta Biotech Ltd, Maquet Critical Care AB, Omnicare Clinical Research AG, and Nestlé. Educational grants were received from Fresenius Kabi; GSK; MSD; Lilly; Baxter; Astellas; AstraZeneca; B. Braun Medical AG, CSL Behring, Maquet, Novartis, Covidien, Nycomed, Pierre Fabre Pharma (Roba Pharma); Pfizer, Orion Pharma. The money went into departmental funds. No personal financial gain applies. All other authors do not have any conflict of interest to declare related to this manuscript.

\section{Publisher's Note}

Springer Nature remains neutral with regard to jurisdictional claims in published maps and institutional affiliations.

Received: 12 August 2019 Accepted: 1 November 2019 Published online: 29 November 2019 


\section{References}

1. Margaras V (2019) Demographic trends in EU regions. European Parliamentary Research Service, January 2019. https://ec.europa.eu/futurium/ en/system/files/ged/eprs-briefing-633160-demographic-trends-eu-regio ns-final.pdf

2. Leblanc G, Boumendil A, Guidet B (2017) Ten things to know about critically ill elderly patients. Intensive Care Med 43:217-219. https://doi. org/10.1007/s00134-016-4477-2

3. Jung C, Wernly B, Muessig JM et al (2019) A comparison of very old patients admitted to intensive care unit after acute versus elective surgery or intervention. J Crit Care 52:141-148. https://doi.org/10.1016/j. jerc.2019.04.020

4. Flaatten H, de Lange DW, Morandi A, Andersen F, Artigas A, Bertolini G et al (2017) The impact of frailty on ICU and 30-day mortality and the level of care in very elderly patients ( $\geq 80$ years). Intensive Care Med 43:1820-1828. https://doi.org/10.1007/s00134-017-4940-8

5. Flaatten H, Garrouste-Orgeas M (2015) The very old ICU patient: a neverending story. Intensive Care Med 41:1996-1998. https://doi.org/10.1007/ s00134-015-4052-2

6. Guidet B, Vallet H, Boddaert J, de Lange DW, Morandi A, Leblanc G, Artigas A, Flaatten H (2018) Caring for the critically ill patients over 80: a narrative review. Ann Intensive Care 8:114. https://doi.org/10.1186/s1361 3-018-0458-7

7. Yu WC, Chou MY, Pen LN, Lin YT, Liang CK, Chen LK (2017) Synergistic effects of cognitive impairment on physical disability in all-cause mortality among men aged 80 years and over: results from longitudinal older veterans study. PLoS One 12:e0181741. https://doi.org/10.1371/journ al.pone.018174

8. Level C, Tellier E, Dezou P, Chaoui K, Kherchache A, Sejourné P, Rullion-Pac Soo AM (2018) Outcome of older persons admitted to intensive care unit, mortality, prognosis factors, dependency scores and ability trajectory within 1 year: a prospective cohort study. Aging Clin Exp Res 30:10411051. https://doi.org/10.1007/s40520-017-0871-z

9. de Lange DW, Guidet B, Andersen FH, Artigas A, Bertolini G, Moreno $R$ et al (2019) Huge variation in obtaining ethical permission for a non-interventional observational study in Europe. BMC Medical Ethics 20(1):39. https://doi.org/10.1186/s12910-019-0373-y

10. Rockwood K, Song X, MacKnight C, Bergman H, Hogan DB, McDowell I et al (2005) A global clinical measure of fitness and frailty in elderly people. CMAJ 173:489-495. https://doi.org/10.1503/cmaj.050051

11. Katz S (1983) Assessing self-maintenance: activities of daily living, mobility, and instrumental activities of daily living. J Am Geriatr Soc 31:721-727. https://doi.org/10.1111/j.1532-5415.1983.tb03391.x

12. Jorm A (2004) The Informant Questionnaire on Cognitive Decline in the Elderly (IQCODE): a review. Int Psychogeriatr 16:1-19

13. Quinn TJ, Fearon P, Noel-Storr AH, Young C, McShane R, Stott DJ (2014) Informant Questionnaire on Cognitive Decline in the Elderly (IQCODE) for the diagnosis of dementia within community dwelling populations. Cochrane Database of Syst Rev. https://doi.org/10.1002/14651858.cd010 079.pub2

14. Evans DC, Cook CH, Christy JM, Murphy CV, Gerlach AT, Eiferman D et al (2012) Comorbidity-polypharmacy scoring facilitates outcome prediction in older trauma patients. J Am Geriatr Soc 60:1465-1470. https://doi.org/ 10.1111/j.1532-5415.2012.04075.x

15. Vincent JL, Moreno R, Takala J, Willatts S, De Mendonça A, Bruining H, Reinhart CK, Suter PM, Thijs LG (1996) The SOFA (Sepsis-related Organ Failure Assessment) score to describe organ dysfunction/failure. On behalf of the working group on sepsis-related problems of the ESICM. Intensive Care Med 22:707-710

16. Guidet B, Flaatten $H$, Boumendil A et al (2018) Withholding or withdrawing of life-sustaining therapy in older adults ( $\geq 80$ years) admitted to the intensive care unit. Intensive Care Med 44:1027-1038. https://doi. org/10.1007/s00134-018-5196-7

17. Flaatten $\mathrm{H}$, de Lange DW, Artigas A et al (2017) The status of ICM research and a future agenda for very elderly patients in the ICU. Intensive Care Med 43:1319-1328. https://doi.org/10.1007/s00134-017-4718-z

18. Pan W (2001) Akaike's information criterion in generalized estimating equations. Biometrics 57:120-125. https://doi.org/10.1111/j.0006341X.2001.00120.x

19. Cole SR, Hernán MA (2004) Adjusted survival curves with inverse probability weights. Comput Methods Programs Biomed 75:45-49
20. Kottner J, Audigé L, Brorson S, Donner A, Gajewski BJ, Hróbjartsson A, Roberts C, Shoukri M, Streiner DL (2011) Guidelines for reporting reliability and agreement studies (GRRAS) were proposed. J Clin Epidemiol 64:96-106. https://doi.org/10.1016/j.jclinepi.2010.03.002

21. Guidet B, de Lange DW, Flaatten H (2018) Should this elderly patient be admitted to the ICU? Intensive Care Med 44:1926-1928. https://doi. org/10.1007/s00134-018-5054-7

22. Flaatten $\mathrm{H}$, Jung $\mathrm{C}$, Vallet $\mathrm{H}$ et al (2019) How does frailty affects outcome? Curr Anesthesiol Rep 9:144

23. Bagshaw SM, Stelfox HT, Johnson JA, McDermid RC, Rolfson DB, Tsuyuki RT et al (2015) Long-term association between frailty and health-related quality of life among survivors of critical illness: a prospective multicenter cohort study. Crit Care Med 43:973-982. https://doi.org/10.1097/ CCM.0000000000000860

24. Hewitt J, Carter B, McCarthy K, Pearce L, Law J, Wilson FV et al (2019) Frailty predicts mortality in all emergency surgical admissions regardless of age. An observational study. Age Ageing 48:388-394. https://doi. org/10.1093/ageing/afy217

25. Hewitt J, Long S, Carter B, Bach S, McCarthy K, Clegg A (2018) The prevalence of frailty and its association with clinical outcomes in general surgery: a systematic review and meta-analysis. Age Ageing 47:793-800. https://doi.org/10.1093/ageing/afy110

26. Theou O, Campbell S, Malone ML, Rockwood K (2018) Older adults in the emergency department with frailty. Clini Geriatr Med 34:369-386. https:// doi.org/10.1016/j.cger.2018.04.003

27. Persico I, Cesari M, Morandi A, Haas J, Mazzola P, Zambon A, Annoni G, Bellelli G (2018) Frailty and delirium in older adults: a systematic review and meta-analysis of the literature. J Am Geriatr Soc 66:2022-2030. https ://doi.org/10.1111/jgs.15503

28. Hayat SA, Luben R, Dalzell N, Moore S, Hogervorst E, Matthews FE et al (2018) Understanding the relationship between cognition and death: a within cohort examination of cognitive measures and mortality. Eur J Epidemiol 33:1049-1062. https://doi.org/10.1007/s10654-018-0439-z

29. Crosby G, Culley DJ, Hyman BT (2011) Preoperative cognitive assessment of the elderly surgical patient: a call for action. Anesthesiology 114:1265-1268. https://doi.org/10.1097/ALN.0b013e31821b1bc8

30. Jorm AF (1994) A short form of the Informant Questionnaire on Cognitive Decline in the Elderly (IQCODE): development and cross validation. Psychol Med 24:145-153

31. McNicoll L, Redlich CA (2003) Screening for preexisting cognitive impairment in older intensive care unit patients: use of proxy assessment. J Am Geriatr Soc 51:689-693. https://doi.org/10.1034/j.1600-0579.2003.00215.x

32. Sacanella E, Pérez-Castejón JM, Nicolás JM, Masanés F, Navarro M, Castro P, López-Soto A (2009) Mortality in healthy elderly patients after ICU admission. Intensive Care Med 35:550-555. https://doi.org/10.1007/s0013 4-008-1345-8

33. Kalra S et al (2015) Comorbidity polypharmacy score and its clinical utility: a pragmatic practitioner's perspective. J Emerg Trauma Shock. 8:224-231. https://doi.org/10.4103/0974-2700.161658

34. Nossaman VE, Larsen BE, DiGiacomo JC et al (2018) Mortality is predicted by comorbidity polypharmacy score but not charlson comorbidity index in geriatric trauma patients. Amer J Surgery 216:42-45. https://doi. org/10.1016/j.amjsurg.2017.09.011

35. Housley BC, Stawicki SP, Evans DC, Jones C (2015) Comorbidity-polypharmacy score predicts readmission in older trauma patients. J Surg Res 199:237-243. https://doi.org/10.1016/j.jss.2015.05.014

36. Sammy I, Lecky F, Sutton A, Leaviss J, O'Cathain A (2016) Factors affecting mortality in older trauma patients-a systematic review and meta-analysis. Injury 47:1170-1183. https://doi.org/10.1016/j.injury.2016.02.027

37. Justiniano CF, Evans DC et al (2015) Comorbidity-polypharmacy score predicts in-hospital complications and the need for discharge to extended care facility in older burn patients. J Burn Care Res. 36:193-196. https://doi.org/10.1097/BCR.0000000000000094

38. Sprung CL, Ricou B, Hartog CS et al (2019) Changes in end-of-life practices in european intensive care units from 1999 to 2016. JAMA 2:1-12. https://doi.org/10.1001/jama.2019.14608

39. Guidet B, Leblanc G, Simon T et al (2017) Effect of systematic intensive care unit triage on long-term mortality among critically ill elderly patients in France: a randomized clinical trial. JAMA 318:1450-1459. https://doi. org/10.1001/jama.2017.13889 
40. Davies J, Whitlock J, Gutmanis I, Kane SL (2018) Inter-rater reliability of the retrospectively assigned clinical frailty scale score in a geriatric outreach population. Can Geriatr J. 21:1-5. https://doi.org/10.5770/cgj.21.263

41. Shears M, Takaoka A, Rochwerg B et al (2018) Assessing frailty in the intensive care unit: a reliability and validity study. J Crit Care 45:197-203. https://doi.org/10.1016/j.jcrc.2018.02.004
42. Flaatten H, Oeyen S, de Lange DW (2018) Predicting outcomes in very old ICU patients: time to focus on the past? Intensive Care Med 44:13441345. https://doi.org/10.1007/s00134-018-5262-1 